\title{
Variabilidade espacial da textura de um Argissolo Vermelho Amarelo sob cultivo de pastagem e vegetação nativa
}

\author{
Spatial variability of the texture in a Red-Yellow Ultisol under pasture and nature vegetation crop
}

\author{
Julião Soares de Souza Lima ${ }^{*}$ Marcos Antonio Sattler ${ }^{\mathrm{II}}$ Alexandre Cândido Xavier ${ }^{\mathrm{I}}$ \\ Rone Batista de Oliveira ${ }^{\mathrm{III}}$ Renato Ribeiro Passos ${ }^{\mathrm{IV}}$ Paulo César Oliveira ${ }^{\mathrm{I}}$
}

\begin{abstract}
- NOTA-
RESUMO

O conhecimento da variabilidade espacial dos atributos de um solo sob diferentes coberturas auxilia o estudo das alterações ocorridas em razão do manejo. O objetivo deste trabalho foi determinar, com uso da estatística clássica e geoestatística, a variabilidade espacial das frações texturais

pasture area the fractions of coarse and total sand presented larger mean values in relation to the native vegetation, and negative correlation with the altitude of the points samples in the two areas. All of the fractions presented moderate to high spatial dependence in the two areas and with the defined still, with exception of the fine sand and the silt in the pasture. Much of this variability occurs as a function of water erosion.
\end{abstract} de um solo cultivado com pastagem e vegetação nativa. Amostras de solo foram coletadas na profundidade de 0-0,20m, nos pontos de cruzamento de uma malha, com intervalos regulares de $10 \mathrm{~m}$, totalizando 64 pontos em cada área. $\mathrm{Na}$ área de pastagem, as frações areia grossa e total apresentaram valores médios maiores em relação à vegetação nativa e correlações negativas com as altitudes dos pontos amostrais nas duas áreas. Todas as frações texturais apresentaram dependência espacial de moderada a alta nas duas áreas $e$ com o patamar definido, com exceção da areia fina e do silte na pastagem. Grande parte dessa variabilidade ocorre em função da erosão hídrica.

Palavras-chave: distribuição espacial, krigagem, manejo do solo.

\section{ABSTRACT}

The study of the spatial variability of soil attributes under different crop helps the study of changes due the management. This research was carried out to determine spatial variability the particle-size distribution, using of the classic statistic and geostatistics, of a soil cultivated with pasture and native vegetation. Soil samples were collected in the layer 0 $0.20 \mathrm{~m}$, at the crossing points of a regular grid with $10 \mathrm{~m}$ intervals, summing up 64 samples points in each area. In the
Key words: spatial distribution, kriging, soil management.

Independente do histórico de manejo adotado e da cobertura do solo em áreas agrícolas, SOUZA et al. (2003) identificaram que a posição de uma determinada área em uma toposequência influencia a variabilidade espacial dos teores de areia e argila, e a forma da paisagem pode gerar rotas preferenciais para o fluxo de água no escoamento superficial, ocasionando essa variabilidade.

LOMBARDI NETO (1993) ressalta que o solo coberto com uma pastagem bem manejada, de modo que se mantenha uma adequada cobertura do solo, está menos susceptível à erosão hídrica, diminuindo o impacto da gota de chuva e o arraste do solo. Entretanto, segundo SOUZA et al. (2004), esses atributos em Latossolos são estáveis, ou seja, modificam-se pouco ao longo do tempo por ação do intemperismo.

'Departamento de Engenharia Rural, Universidade Federal do Espírito Santo (UFES), 29500-000, Alegre, ES, Brasil. E-mail: limajss@yahoo.com.br.*Autor para correspondência.

"Escola Agrotécnica Federal de alegre (EAFA), Alegre, ES, Brasil.

II'Departamento de Produção Vegetal, UFES, Alegre, ES, Brasil.

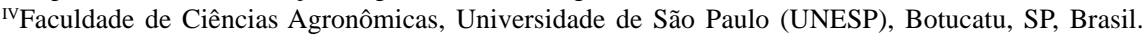


Segundo VIEIRA (2000), o estudo da variabilidade de atributos físicos do solo pode ser realizado pela estatística clássica e a geoestatística. Esta última considera a dependência espacial entre as amostras e as suas posições na área de estudo.

O presente trabalho foi desenvolvido com o objetivo de avaliar a variabilidade espacial das frações texturais de um Argissolo Vermelho Amarelo em uma área sob vegetação nativa, em estado de regeneração, e outra em cultivo de pastagem, por meio da estatística descritiva e da geoestatística.

A área de estudo localiza-se na Bacia Hidrográfica do Itapemirim, sub-bacia do Córrego Horizonte, na área da Escola Agrotécnica Federal de Alegre, Município de Alegre, Epírito Santo. O experimento foi instalado no terço médio de uma encosta de pedoforma convexa, em um Argissolo Vermelho Amarelo com textura argilosa (EMBRAPA, 1999), sob pastagem (PA) e vegetação nativa em regeneração (VN), com declividade média entre 30 e 45 graus e altitude em torno de $150 \mathrm{~m}$. As amostras do solo para determinação das frações granulométricas (argila, silte, areia grossa, areia fina e areia total) foram coletadas na profundidade de $0-0,20 \mathrm{~m}$, em uma malha regular de $10 \times 10 \mathrm{~m}$, totalizando 64 pontos amostrais por área. A área sob PA é constituída de braquiária (Brachiaria decumbens) com, aproximadamente, seis anos de implantação com aração em nível feita com tração animal. Anteriormente, essa área era coberta com pastagem nativa. A área de VN é distante de $20 \mathrm{~m}$ da PA e compreende um fragmento de vegetação secundária em regeneração natural há aproximadamente 30 anos.

Primeiramente, os dados foram analisados por meio da estatística descritiva, em que foi testada a normalidade dos dados pelo teste Shapiro-Wilk's $(\mathrm{P} \leq 0,05)$. Para a comparação dos valores médios das frações texturais entre as áreas sob PA e VN, realizouse o teste $t(P \leq 0,05)$. A verificação da presença do chamado efeito proporcional também foi realizada, com os dados dispostos em linhas e colunas para o cálculo da correlação entre a média e o desvio padrão, em busca da estacionaridade mínima necessária ao uso da geoestatística. Em seguida, a existência da dependência espacial de cada atributo do solo foi comprovada pelo semivariograma experimental, definindo os parâmetros: efeito pepita $\left(\mathrm{C}_{0}\right)$, alcance (a) e patamar $\left(\mathrm{C}_{0}+\mathrm{C}_{1}\right)$. O índice de dependência espacial (IDE) foi calculado pela relação $\mathrm{C}_{1} /\left(\mathrm{C}_{0}+\mathrm{C}_{1}\right)$, em que IDE $<25 \%$ é baixo, $25 \%<$ IDE $<75 \%$ é médio e IDE $>75 \%$ é alto, conforme classificação de ZIMBACK (2001). Definidos os semivariogramas teóricos, fez-se a interpolação pelo método da krigagem ordinária para a determinação de valores em locais não amostrados.

Os valores da média e mediana das frações do solo foram semelhantes, tendendo a uma distribuição simétrica (Tabela 1). Todas as frações texturais apresentaram distribuição normal. Os coeficientes de assimetria (Cs) e curtose (Ck) próximos de zero confirmam a tendência dos dados à normalidade. Segundo a classificação proposta por WARRICK \& NIELSEN (1980), as frações areia fina (AF) na área de PA e areia total (AT) na VN apresentaram um CV baixo ( $<12 \%)$, enquanto que as demais frações apresentaram média variação $(\mathrm{CV}<60 \%)$. O silte apresentou os maiores CVs (19\% e 21\%), indicando que essa variação pode estar relacionada ao seu processo de determinação em laboratório, por incorporar parte da variabilidade existente nas frações areia e argila.

A área sob VN apresentou valores médios significativos e superiores nas frações mais finas (argila, silte) em relação à PA, com exceção para a areia fina (AF), que não apresentou diferença. Já em relação à areia grossa (AG), a situação se inverte, sendo maiores os teores apresentados no solo na área sob PA em relação à VN. A areia total (AT) apresentou maiores valores no solo sob PA que no solo sob VN. A maior cobertura vegetal na área sob VN, e a presença de resíduos orgânicos na superfície do solo podem ter favorecido esse comportamento, servindo de proteção contra a perda de solo na erosão hídrica, impedindo que as gotas de chuva atinjam diretamente o solo evitando, desse modo, a desagregação de suas partículas. Resultados semelhantes foram obtidos por SPERA (1996), em que solos em condições de mata apresentaram maiores porcentagens de frações mais finas, como argila, em relação a solos sob campo (pastagem).

$\mathrm{Na}$ análise de correlação das frações texturais com a altitude de cada ponto amostral, observou-se que na PA os dados demonstraram correlação significativa positiva para Sil $(r=0,65)$ e negativa para AT $(r=-0,58)$. Na VN, a correlação foi significativa e positiva para o teor de ARG $(r=0,37)$ e negativa para todas as frações de areia ( $\mathrm{r}$ entre $-0,40$ e 
Tabela 1 - Dados da estatística descritiva das frações texturais do solo nas áreas sob pastagem (PA) e vegetação nativa (VN).

\begin{tabular}{|c|c|c|c|c|c|c|c|c|c|c|c|}
\hline \multirow{2}{*}{ Atrib. } & \multirow{2}{*}{ Unid. } & \multirow{2}{*}{ Méd } & \multirow{2}{*}{ Md. } & \multirow{2}{*}{ S } & \multicolumn{2}{|c|}{---------Valores---------- } & \multicolumn{3}{|c|}{----------Coeficientes---------- } & \multicolumn{2}{|c|}{-----Normalidade----- } \\
\hline & & & & & Min. & Max & $\mathrm{CV}$ & $\mathrm{Ck}$ & Cs & $\mathrm{W}$ & P.val. \\
\hline & & & & & $-F \mathrm{~d}$ & (111-- & 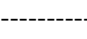 & -------' & -------- & --------- & --------- \\
\hline ARG & $\left(\right.$ g. $\left.\mathrm{kg}^{-1}\right)$ & 421,13 & 422,60 & 54,73 & 290,20 & 541,90 & 13,00 & $-0,18$ & $-0,16$ & 0,99 & $0,90 *$ \\
\hline $\mathrm{AF}$ & (g. $\left.\mathrm{kg}^{-1}\right)$ & 98,88 & 98,57 & 10,56 & 75,63 & 122.59 & 10,68 & $-0,74$ & 0,004 & 0,98 & $0,55^{*}$ \\
\hline AG & (g. $\left.\mathrm{kg}^{-1}\right)$ & 254,18 & 252,92 & 51,87 & 156,81 & 374,11 & 20,4 & $-0,51$ & 0,21 & 0,98 & $0,45^{*}$ \\
\hline $\mathrm{AT}$ & (g. $\left.\mathrm{kg}^{-1}\right)$ & 357,91 & 351,68 & 60,49 & 243,62 & 516,52 & 16,90 & $-0,25$ & 0,34 & 0,98 & $0,49 *$ \\
\hline Sil & (g. $\mathrm{kg}^{-1}$ ) & 220,96 & 218,57 & 46,29 & 141,19 & 329,18 & 21,00 & $-0,85$ & 0,23 & 0,97 & $0,12^{*}$ \\
\hline ARG & (g. $\left.\mathrm{kg}^{-1}\right)$ & 448,55 & 447,80 & 55,70 & $\begin{array}{c}\text {---Veget } \\
309,30\end{array}$ & $\begin{array}{c}\text { nativa-- } \\
573,80\end{array}$ & 12,42 & $-0,04$ & 0,01 & 0,98 & 0,50* \\
\hline $\mathrm{AF}$ & (g. $\mathrm{kg}^{-1}$ ) & 102,32 & 102,25 & 9,43 & 86,17 & 127,19 & 13,88 & $-0,20$ & 0,44 & 0,99 & $0,82^{*}$ \\
\hline AG & (g. $\mathrm{kg}^{-1}$ ) & 222,04 & 219,65 & 30,83 & 157,94 & 294,54 & 12,43 & $-0,28$ & 0,14 & 0,98 & $0,26^{*}$ \\
\hline $\mathrm{AT}$ & (g. $\mathrm{kg}^{-1}$ ) & 322,15 & 317,04 & 36,07 & 256,97 & 410,19 & 11,20 & $-0,34$ & 0,42 & 0,98 & $0,32 *$ \\
\hline Sil & (g. $\left.\mathrm{kg}^{-1}\right)$ & 225,79 & 232,41 & 42,83 & 136,61 & 294,42 & 19,00 & $-0,78$ & $-0,36$ & 0,96 & $0,06^{*}$ \\
\hline
\end{tabular}

Atrib. - atributo; * Distribuição normal; ARG - fração argila; Sil - fração silte; AF - fração areia fina; AG - fração areia grossa, AT - fração areia total; Méd - média; Md - mediana; Min. - valor mínimo; Max. - valor máximo; S - desvio padrão; Coeficientes: de variação (CV), $\mathrm{Ck}$ - curtose e Cs - assimetria.

-0,45). Essa correlação negativa com a declividade na área de $\mathrm{VN}$ pode ser influenciada pela presença de uma mudança da pedoforma convexa para a côncava na parte inferior esquerda da área, que favorece acumulação relativa das partículas maiores e mais densas nas cotas inferiores do terreno durante o processo erosivo no período chuvoso. O processo erosivo ocorre pela degradação superficial pelas gotas de chuva. Já o transporte das partículas de solo no escoamento superficial com a deposição ocorre em razão de a carga de sedimentos exceder a sua capacidade de transporte.

$\mathrm{Na}$ análise do efeito proporcional, somente as frações AG e AT na VN apresentaram efeito significativo, sendo, portanto, trabalhado com os resíduos na análise espacial, com ajuste do modelo esférico e alto índice de dependência espacial. A análise espacial na área sob PA e as frações ARG, AG e AT apresentaram o mesmo padrão de dependência espacial, com ajuste ao modelo esférico e com o alcance variando de 35 a 39m. Isso quer dizer que amostras separadas por distâncias menores que o alcance são correlacionadas umas às outras, o que permite que sejam realizadas interpolações para espaçamentos menores do que o utilizado na amostragem. Oíndice de dependência (IDE) foi moderado e alto, respectivamente, para a ARG e a AG e a AT. Cabe ressaltar que, para a implantação da PA, o solo foi revolvido com aração de tração animal, com deslocamento em nível. O Sil na PA apresentou o modelo linear, mostrando que a malha amostral construída não teve densidade de pontos suficientes para definir a sua dependência espacial. Já a fração AF apresentou ausência de dependência espacial, permitindo concluir que, nessa escala, a sua distribuição se apresenta de forma independente no espaço, ou seja, considerada ao acaso.

Na área de VN, ajustou-se o modelo esférico com o alcance variando de 17 a 20m para ARG, Sil, AG e AT, sendo, portanto, menor que na área sob PA e com alto índice de dependência espacial. Essa diferença nos valores do alcance, para o mesmo solo em áreas próximas, pode ser um indicativo da influência da cobertura, do uso, do manejo adotado e também decorrência do processo de erosão hídrica. Observa-se, na figura 1, a distribuição espacial das frações granulométricas, nas duas áreas, interpoladas por krigagem ordinária.

Concluiu-se que, na área de vegetação nativa, todas as frações do solo apresentaram alta dependência espacial, enquanto que, na área sob pastagem, as frações argila e a areia grossa apresentaram moderada dependência. A área sob vegetação nativa apresentou maior concentração de argila e silte, indicando redução na movimentação dessas partículas no escoamento superficial. 

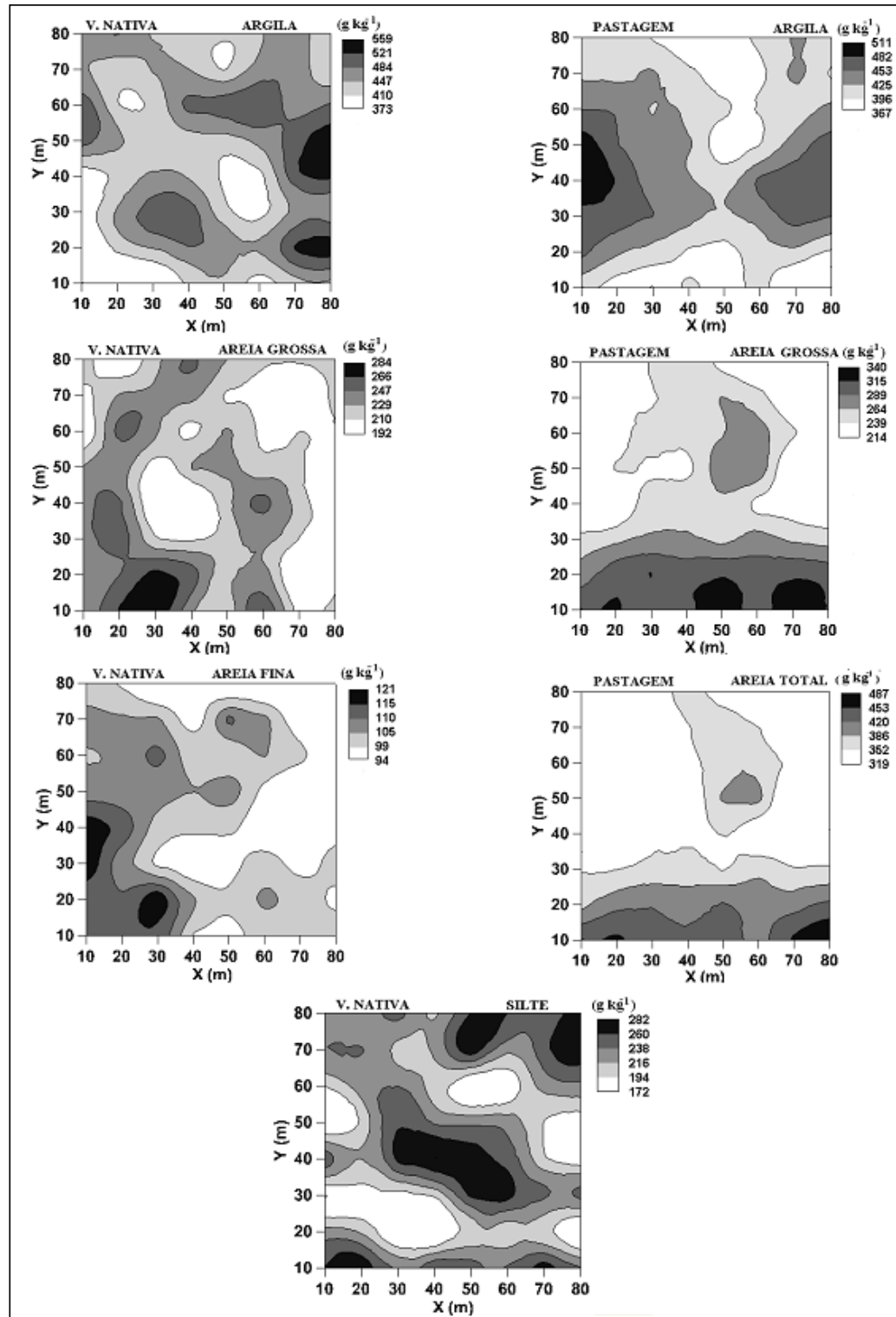

Figura 1 - Mapas de isolinhas da distribuição espacial das frações granulométricas nas duas áreas.

\section{REFERÊNCIAS}

EMPRESA BRASILEIRA DE PESQUISA AGROPECUÁRIA Sistema brasileiro de classificação do solo. Brasilia: EMBRAPA, CNPS, 1999. 412p.

LOMBARDI NETO, F. Degradação de pastagens. In: ENCONTRO SOBRE RECUPERAÇÃO DE PASTAGENS, 1993, Nova Odessa. Anais... Nova Odessa: Instituto de Zootecnia, 1993. p.49-60.

SOUZA, C.K. et al. Influência do relevo na variação anisotrópica dos atributos químicos e granulométricos de um latossolo em Jaboticabal - SP. Engenharia Agrícola, Jaboticabal, v.23, n.3, p.486-495, 2003.

SOUZA, Z.M. et al. Variabilidade espacial da textura de um latossolo vermelho amarelo eutroférrico sob cultivo de cana-de açúcar. Engenharia Agrícola, Jaboticabal, v.24, n.2, p.309319, 2004.
SPERA, S.T. et al. Inter-relações entre propriedades físicohídricas do solo e a ocorrência de vegetação de mata e campo adjacentes no Alto Rio Grande (MG). Ciência e Agrotecnologia, Lavras, v.20, n.2, p.178-182, 1996.

VIEIRA, S.R. Geoestatística em estudo de variabilidade especial do solo: In NOVAIS, R.F. et al. Tópicos em ciência do solo. Viçosa: Sociedade Brasileira de Ciência do Solo, 2000. V.1, p.155

WARRICK, A.W.; NIELSEN, D.R. Spatial variability of soil physical properties in the field. In: HILLEL, D. (Ed.). Application of soil physics. New York: Academic, 1980. p.319-324.

ZIMBACK, C.R.L. Análise especial de atributos químicos de solos para fins de mapeamento da fertilidade. 2001. 114f. Tese (Livre-Docência em Levantamento do solo e fotopedologia) - FCA-UNESP, Botucatu, SP. 